\title{
ENTREVISTA: PROFESSOR RICARDO TADEU LOPES
}

Neuvânia Curty Ghetti ${ }^{1}$

curty.quimicarqueologica@gmail.com

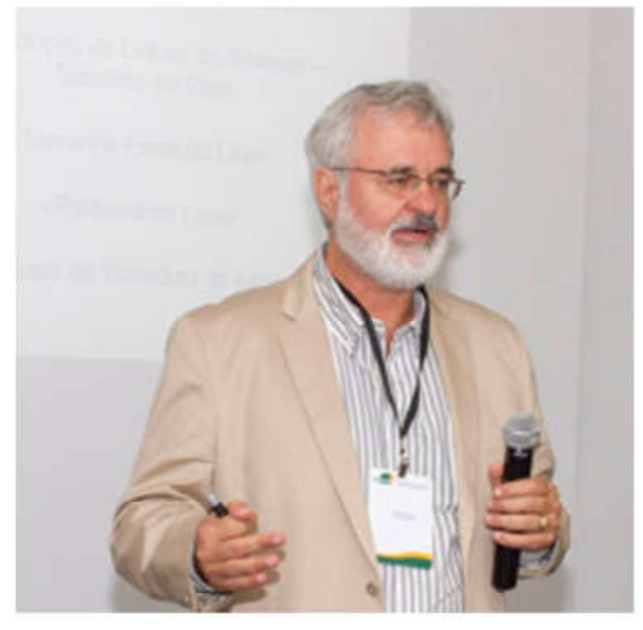

Em agosto de 2016, a revista Clio

Arqueológica entrevistou o Professor Ricardo Tadeu. Formado em Física, com mestrado e doutorado em engenharia nuclear, é professor titular da UFRJ desde 2002. Inicialmente dedicou-se à produção de instrumentação nuclear, especificamente na construção de módulos eletrônicos, como instrumentos e detectores de irradiação. Atualmente o Professor Ricardo desenvolve suas pesquisas no laboratório de Instrumentação Nuclear. Esse laboratório vem migrando e ampliando sua área de atuação para outras técnicas de aplicações nucleares, entre as quais fazem parte a radiografia digital, a tomografia computadorizada e as técnicas analíticas de

\footnotetext{
${ }^{1}$ Departamento de Arqueologia, UFPE.
} 
fluorescências por Raios X e de difração de Raios X. Essas duas últimas são as que ocupam a maior parte do tempo de suas pesquisas.

O laboratório também atua e aporta conhecimento em outras áreas, desde aspectos voltados para a indústria, passando pela Medicina e pela Biologia. Entretanto, no caso da Arqueologia essa interação se deu de forma paralela e diferenciada, pois em 2010 o Professor Ricardo foi convidado para integrar o programa de pósgraduação em Arqueologia da UFRJ, ligado ao Museu Nacional. Nesse caso sua atuação se dá através da disciplina Técnicas Atômicas Nucleares Aplicadas à Arqueologia e como suporte às dissertações e teses que necessitam do respaldo da física nuclear.

\section{"Basicamente meu} contato com Arqueologia se deu a

\section{partir de 1994, quando participei de um colóquio.}

Clio Arqueológica: A Arqueologia

como área interdisciplinar tem se respaldado cada vez mais em pesquisas nas áreas da Física e da Química. Como o senhor entrou em contato e quais os resultados alcançados nessa interação entre a Arqueologia e a energia nuclear?

Professor Ricardo Tadeu: Basicamente meu contato com a Arqueologia se deu a partir de 1994, quando participei de um colóquio sobre Conservação e Restauração de Patrimônio Histórico e Cultural, onde se apresentavam as técnicas analíticas que eram aplicadas aos bens culturais e ao patrimônio histórico. Naquela época nossa ênfase era a Física aplicada à Medicina, e, a partir daquele evento, entrei em contato com um 
professor da Itália, o Professor Roberto Cesário. Então, começamos a fazer parcerias. Ele também é físico e, como na Itália a parte de patrimônio histórico e de bens culturais é bastante forte e ampla, há um desdobramento da física na prática de restauração e conservação dos monumentos.

Em 2000 recebi um estudante da Itália, da Universidade de Sassari, na Sardenha, para ficar um ano com a gente, e então começou minha interação o Museu Nacional, pois, para tentar fazer um trabalho de cooperação, procuramos, na época, o diretor do Museu para falarmos sobre as técnicas que poderíamos aplicar. Para minha surpresa, ele falou que não podia ajudar, pois o problema do Museu era outro. Estava cheio de cupins.

Ele nos questionou se podíamos descupinizar tudo. Bem, eu tinha uma ideia de como tentar acabar com os cupins, mas não era minha especialização nem o que eu pretendia fazer. Ele não era arqueólogo nem antropólogo, era um professor de Direito que ganhou a direção do Museu. O problema dele era a conservação do Museu, para que não caísse o teto, não desabasse e danificasse o acervo.

\section{"Restou-me deixar lá nosso trabalho."}

Restou-me deixar lá nosso trabalho e ao que nos propúnhamos. Anos depois fomos procurados por uma pesquisadora da Fundação Oswaldo Cruz que interagia também com o Museu; ela nos propôs um trabalho de identificação de um fóssil. A intenção era descobrir a veracidade do fóssil, ou seja, se era ou não um fóssil, supostamente

de Lagoa Santa (no Estado de Minais Gerais). Aí começou de fato a primeira interação com a Arqueologia. Aplicamos as técnicas de identificação e chegamos à conclusão de 
que aquele fóssil era falso. Isso resultou no nosso primeiro trabalho publicado nessa área, que integra a Arqueologia, a Física e um pouco de Química através de técnicas analíticas.

A partir de então essa interação começou a crescer, pois entramos em contato com outros pesquisadores do Museu. Mais tarde a Professora Tânia Andrade Lima nos procurou e começamos a trabalhar com cerâmica marajoara. Ela tinha como objetivo identificar a migração entre o norte e o sul desse grupo indígena através da cerâmica.

\section{"Nosso trabalho aqui é de cooperação."}

A gente começou a aplicar essa interação também com um egiptólogo, na parte das múmias egípcias que existem no Museu, e de lá para cá a coisa foi evoluindo. Desde então nosso trabalho com arqueólogos vem se aprofundando cada vez mais.

Clio Arqueológica: Os resultados alcançados nas pesquisas que foram e que estão sendo realizadas aqui no Instituto Alberto Luiz Coimbra, de pós-graduação, e nas pesquisas em Engenharia, no programa de Energia Nuclear, seriam produto de uma postura de especialistas que buscam trabalhar em conjunto com outras áreas? O que representa isso para a pesquisa hoje no Brasil?

Professor Ricardo Tadeu: A nossa postura é de colaboração, e isso é uma coisa bastante interessante. Às vezes temos que criar grupos para buscarmos financiamento para pesquisas, pois os editais estão com essa exigência. E, para tanto, você precisa interagir com alguém ou com outro grupo. 
Outro aspecto é o estímulo, pois, como nosso trabalho aqui é de cooperação e como a gente sempre desenvolveu técnicas, essas técnicas têm que ser aplicadas para terem utilidade. Acontece que qualquer técnica desenvolvida tem que ter uma aplicabilidade nas outras áreas, e, como somos físicos, não adianta, por exemplo, desenvolver uma determinada técnica física na Medicina se eu não sou o médico. Então, para desenvolver e validar a técnica a gente busca essa interação, essa cooperação.

Com a Arqueologia acontece a mesma coisa. Anteriormente a única técnica que se conhecia de interação entre a Física e a Química com a Arqueologia era a parte de datação. Hoje não. Além da datação temos a caracterização material e o estudo de espécies, a origem, etc.

Então, tudo isso foi alcançado com essa integração com pessoas de outras áreas. Trata-se de uma postura interdisciplinar e que tem que ter as duas pontas, ou seja, é preciso trabalhar em conjunto desde início.

No nosso caso, uma das técnicas que nos tem permitido interagir com outras áreas é a radiografia digital, que é difícil de fazer. Com nosso conhecimento adquirido, nós já prestamos serviços, por exemplo, para a análise de quadros no Museu do Café, em Santos, e no Museu do Ipiranga, em São Paulo.

E esses objetivos com outras áreas do conhecimento são o grande estímulo dessa cooperação. Além do mais, a divulgação do nosso trabalho com os colaboradores é também outro estímulo para atuarmos em conjunto. Sem divulgação da colaboração e da interação a gente hoje não consegue nada. 
Clio Arqueológica: Então que novos métodos analíticos e arqueométricos estão sendo aplicados e desenvolvidos e o que nós podemos esperar dessa cooperação?

Professor Ricardo Tadeu: Atualmente o nosso laboratório tem quatro linhas de atuação. A da radiografia, a da tomografia, a da fluorescência e a da datação.

Hoje os colaboradores passaram a ser uma espécie de clientes, pois, ao saberem que temos essas técnicas e tendo os problemas, nos procuram para ajudar na resolução.

Entrando na área de história da arte e restauração de pinturas a gente participou da restauração de um quadro do século XIX que representa a primeira missa no Brasil; esse quadro fica no Museu de Belas Artes aqui do Rio de Janeiro. Nesse trabalho, além das 180 radiografias feitas, num quadro que tem aproximadamente quatro por três metros, fizemos também a análise dos pigmentos para poder ajudar na sua restauração.

\section{"Atualmente o} nosso laboratório tem quatro linhas de atuação."

Nesse caso desenvolvemos um método para aquele objetivo específico e elaboramos uma técnica adequada àquele objeto. Por exemplo, antes, para radiografarmos um quadro, era empregada uma técnica na qual se utilizava um filme convencional, que hoje foi substituído por um filme digital direto e que mostra a radiografia em tempo real.

Hoje em dia é possível, por exemplo, através de equipamentos portáteis — que passaram a ser desenvolvidos no nosso laboratório — , fazer análises de fluorescência para 
utilização no campo. Fizemos aqui um protótipo porque percebemos que cada situação exige uma solução diferente; instrumentos comprados podem até ser úteis, mas não vão resolver $100 \%$ dos problemas da Arqueologia. Temos que estar constantemente desenvolvendo equipamentos. Isso faz parte do nosso trabalho. É assim que conseguimos solucionar os problemas.

Clio Arqueológica: Podemos dizer então que a Engenharia Nuclear e os métodos atômicos nucleares para análises não destrutivas vêm contribuindo de forma significativa para o aprofundamento do conhecimento da Arqueologia no Brasil?

Professor Ricardo Tadeu: Eu posso dizer que sim. Essa contribuição se dá em duas vias. Em uma delas, a Arqueologia apresenta os problemas; na outra, a gente apresenta e tenta implementar as técnicas para solução desses problemas.

Por exemplo, hoje nós temos um estudo de materiais cerâmicos através do qual se descreve como foi a fabricação desse material. constantemente
desenvolvendo

"Temos que estar equipamentos."

Vou falar também de outro

trabalho que hoje é o nosso carro-chefe: uma pesquisa que estamos desenvolvendo, mais ou menos, ao longo de oito anos que é a análise de peças de ouro do Peru antes da colonização. Estamos estudando os processos metalúrgicos desses artefatos, que são compostos por ouro e por prata. Queremos saber como eram feitos, como eram soldados esses vestígios em ouro e prata, se era através de martelos ou não. A gente vem estudando e procurando entender essas questões e com isso tenta contribuir para as pesquisas 
arqueológicas. Cito esses casos porque são exemplos de situações em que tivemos que desenvolver técnicas de análise específicas.

Clio Arqueológica: Nessa perspectiva, como a Engenharia Nuclear contribui para os estudos arqueológicos no Brasil de materiais cerâmicos e registros rupestres e para os estudos paleontológicos em materiais ósseos?

Professor Ricardo Tadeu: Bem, quanto aos estudos arqueológicos, nossa técnica é basicamente uma técnica de caracterização: caracterizamos segundo as imagens ou a parte de elementos químicos presentes nas amostras.

Em relação à paleontologia, verificamos parte da estrutura óssea e, hoje, empregamos uma técnica para ver a formação da estrutura óssea e tentar identificar a espécie. Assim conseguimos um diagnóstico correto. Isso é bastante importante.

Nos registros rupestres, também a análise dos pigmentos utilizados é uma coisa relevante, e eu acho que pode contribuir para a caracterização e o padrão desses registros.

Clio Arqueológica: Diante dessas perspectivas de estudos, quais seriam, na sua avaliação, os resultados concretos? Quer dizer, hoje em dia e com os aperfeiçoamentos tecnológicos quais foram os principais resultados alcançados nessa relação para a preservação do patrimônio arqueológico?

Professor Ricardo Tadeu: O que a gente faz de concreto e como empregamos essa interação implicam em que não adianta apenas pegar uma peça e fazer uma análise, pois eu não saberia concluir a pesquisa. Por outro lado, saber a procedência, a maneira do preparo da cerâmica, por exemplo, ou como o artista naquela época moldava essas peças, 
como ele traçava seus desenhos e seus riscos, suas pinturas, e quais pigmentos utilizava é fruto desse trabalho e dessa tecnologia que nós aplicamos e cujos resultados podem facilitar a vida de quem for conservar e restaurar. A maneira de conservar e a maneira de restaurar podem ser auxiliadas por essas técnicas.

Clio Arqueológica: A graduação em Arqueologia na UFPE enfatiza a necessidade de interação com as ciências exatas, pois os alunos também são induzidos a se capacitarem em ferramentas quantitativas em suas pesquisas. Em sua opinião, qual é o maior desafio que o aluno de Arqueologia pode enfrentar ao agregar nas suas pesquisas os métodos para análise não destrutivos da Engenharia Nuclear e da Arqueometria?

Professor Ricardo Tadeu: Na nossa experiência aqui, não trabalhamos com alunos da graduação. Nossa interação se dá com pessoas de outras formações e que se interessaram pela Arqueologia. Tem o pessoal de História, de Biologia e outras ciências que no fundo irão se especializar em Arqueologia.

A graduação em Arqueologia já prevê que o aluno vai ter uma formação naquela área, com isso acho bastante interessante que depois ele também possa, nesse curso, aprender as técnicas de análise que irão ajudá-lo na sua carreira e na sua aplicação no campo e na profissão.

Não vejo dificuldade nenhuma porque ele está num processo de formação, então, se está num processo de formação, as dificuldades são inerentes à sua área, e as disciplinas da Física e da Química interagem com a Arqueologia através de técnicas analíticas. Acho que, nesse contexto, essas disciplinas são facilmente absorvidas. Não vejo, por exemplo, como um aluno do curso de Arqueologia pode ter dificuldade ou entrave com a Física ou 
a Química se ele absorver pequenos conteúdos de Matemática, que o levarão a entender as técnicas e aplicá-las nos seus problemas futuros no campo ou onde ele for trabalhar.

Clio Arqueológica: No caso da pós-graduação, quais as maiores dificuldades dos alunos de Mestrado e Doutorado em optar por projetos de pesquisas que tenham como objeto de estudo os vestígios arqueológicos?

Professor Ricardo Tadeu: Nesse caso, por exemplo, nós temos dois tipos de alunos: os alunos que vêm da Arqueologia com formação em Ciências Sociais ou ciências da saúde e os alunos que vêm das ciências exatas. Então são duas dificuldades, ou seja, duas situações inversas.

Os das ciências exatas podem migrar para a Arqueologia e os das ciências humanas também podem migrar para as ciências exatas. Isso acontece. Para resolver esse problema, o aluno tem que ter o apoio de professores das duas áreas.

Não adianta, por exemplo, oferecer um tema para uma tese de doutorado ou para uma dissertação de mestrado em Arqueometria sem que exista uma cooperação entre áreas.

Veja o caso de um aluno de Física. Ele até pode desenvolver uma técnica arqueométrica com possibilidades de utilização, mas a dupla orientação facilitará a vida dele e a nossa. Motivar o aluno nessa área é fascinante, pois, nas áreas de Arqueologia e de bens culturais e do patrimônio histórico, você se depara com um vestígio material e começa a indagar como alguém, há muito tempo atrás, construiu ou produziu aquele objeto. Isso é uma grande motivação. 
Estudar os processos de manufatura é motivador. Entrar no Museu de Belas Artes, por exemplo, que estuda as pinturas dos séculos XVIII e XIX, e tentar entender o artista, tentar entender porque se usou um pigmento e não outro é muito interessante. Quando a gente faz a radiografia, descobre as tendências no desenho dele, que às vezes caminhavam para um lado e mudou para outro, ou seja, apagou aquele desenho inicial, mas que fica registrado; no processo de radiografia, poder ver essa tendência do artista é bastante motivador. Mas sem as duas áreas, nós da ciência exata não faríamos nada, e o pessoal da Arqueometria também não faria nada sem a gente. Tem que ter união.

Clio Arqueológica: Quais seriam então as perspectivas ou até as metas e os desejos para os laboratórios que trabalham com Arqueometria e para os grupos de pesquisa de caracterização de materiais com radiação ionizante num

futuro próximo?

\section{"Hoje o nosso cenário é}

Professor Ricardo Tadeu:

Hoje o nosso cenário é ruim. Aqui o nosso trabalho está inserido num centro de tecnologia. Aqui a gente tem a Cope e o Instituto da Pósgraduação. A gente se situa próximo a uma unidade do Centro de Pesquisa da Petrobras, então o nosso carro-chefe gira em torno da aplicação industrial. Ocorre que o nosso grupo hoje é composto por $80 \%$ de estudos que visam à aplicação industrial e 20\%, eu diria, voltados para a Arqueometria e para a Arqueologia e obras de artes. Quem financia o nosso laboratório hoje é a 
indústria e, como as técnicas são desenvolvidas para indústria, a maioria das pesquisas é voltada para essa área.

Mesmo assim a interação entre Arqueologia e Física é motivadora. Então, esse trabalho de cooperação que estamos fazendo consiste em desenvolver pequenos sistemas de imagens de radiografia e de tomografia para examinar as peças de museus e dar um diagnóstico preciso. Fazemos isso com recursos da indústria.

Clio Arqueológica: Levando em consideração que a maioria dos recursos são voltados para as pesquisas para a indústria, como o senhor consegue trazer alunos para trabalharem com Arqueometria?

Professor Ricardo Tadeu: A perspectiva e a nossa meta é continuarmos esses trabalhos e, para isso, temos selecionado alunos que têm interesse nessa área.

Nossa atuação é, mais ou menos, a seguinte: nós fazemos propaganda de tudo que produzimos, e isso tende a despertar o interesse dos alunos quando têm que escolher os seus temas de pesquisa.

Então, hoje, nosso grupo está enraizado em outros institutos. Já tem gente na Universidade do Estado do Rio de Janeiro e até nos IFRJ (antigas escolas técnicas) que passou por aqui. Temos já um grupo de formados que se especializou em técnicas nucleares para aplicação em Arqueometria. Acredito, portanto, que essa área de pesquisa já está enraizada e vai crescer ainda mais. 
Vejo que tem um futuro bastante interessante, e, além do mais, é muito gostoso de se pesquisar, porque você trabalhar com tubulações, onde não tem arte, não tem nada, não tem história, só tem petróleo, é um pouco chato.

Clio Arqueológica: Professor, obrigado pela entrevista. Deseja fazer mais alguma observação?

Professor Ricardo Tadeu: Quero agradecer a sua motivação e espero que nossa conversa sirva para divulgar ainda mais esse tipo de interação e dizer que estou bastante interessado na área de Arqueometria.

Clio Arqueológica: Muito obrigado pela atenção e disponibilidade de conversar com a gente da revista Clio Arqueológica. 